\title{
The Perceived Fairness of
}

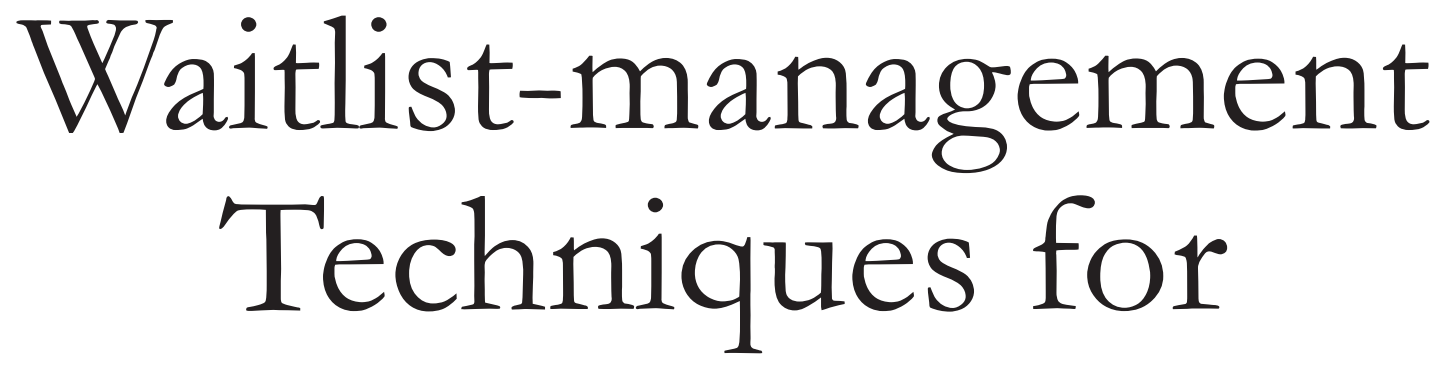
Restaurants

by KELLY A. MCGUIRE and SHERYL E. KIMES

According to a study of the fairness of four common, revenue-enhancing, waitlist-management techniques, restaurants can violate first-come, first-served expectations in seating waiting customers. However, any manipulations to the queue must be done carefully and with a full explanation. Faced with one of several scenarios in which a restaurant violated the firstcome, first-served approach, respondents determined that matching waiting parties to available tables based on party size could be viewed as fair, as could allowing guests to call ahead to place their names on the waitlist. On the other hand, taking reservations for large parties drew mixed reviews, and seating VIPs ahead of all guests was generally viewed as unfair. In all cases, respondents thought explaining a policy improved fairness perceptions.

Keywords: restaurant revenue management; waitlist management; fairness; call-ahead seating; VIP seating; large-party reservations; party-size seating

$\mathrm{R}$ estaurant revenue management can be defined as seating the right customer at the right seat at the right time and for the right price so as to maximize revenue. The problem restaurant managers face in attempting to fulfill that policy during busy 
periods is deciding which parties should be seated at which tables and at what time. While some restaurants use reservations to help with this decision, many restaurants rely primarily on walk-in business and, when the restaurant is busy, must ask customers either to wait in a physical queue or to put their names on a waitlist for a table. ${ }^{1}$ In these situations, managers usually accept customers' requests on a first-come, first-served basis and seat the waiting customers without considering how much revenue that customer or party will bring in. A contrast to that first-come, first-served approach is to use one of several common waitlist-management techniques to select the "right" customers from the waitlist.

Since these techniques violate the firstcome, first-served assumption that governs most waiting lines, however, some managers are reluctant to use any of them for fear of customer backlash. In fact, research has shown that customers will punish a business that they perceive as behaving unfairly by refusing to patronize that firm in the future. ${ }^{2}$

The purpose of our research was to determine how customers of restaurants that do not take reservations react to the following common waitlist-management techniques that violate first-come, firstserved expectations. Those techniques are as follows: seating by party size (matching party size to table size), giving priority to VIP customers (seating important or valuable customers ahead of other customers), taking reservations only for large parties (i.e., parties of eight or more), and using call-ahead seating (customers telephone in advance of arrival to be placed on the waitlist). In addition, we tested whether gaining an advantage from the policy (i.e., having a reduced waiting time) affected perceptions of that policy's fairness.
We first briefly define each policy, followed by a review of the relevant research on the topic of fairness. Then, the results of our study will be presented, along with the implications for managers and researchers. The article concludes with the study's limitations and opportunities for future research.

\section{Four Waitlist-management Policies}

\section{Party-size Seating}

Party-size seating entails seating parties at right-sized tables (parties of one or two at tables of two, and parties of three or four at tables of four). If parties are matched to table size, more seats in the restaurant will be filled, which will increase both seat utilization and revenue. ${ }^{3}$

\section{VIP Seating}

Many restaurants give seating priority to important customers (VIPs) because they are loyal (and management hopes that they will continue to return) or because they are otherwise valuable to the restaurant. For example, a restaurant may prefer to seat a regular customer or a friend of the owner before seating other guests, or a casino restaurant may prefer to seat its high-spending gamblers before seating other customers. Some restaurants give seating priority to celebrities because they feel catering to celebrities brings status to the restaurant.

\section{Large-party Reservations}

Some restaurants take reservations only for large parties (e.g., greater than six or eight persons), so that they can better plan when and where the party will be seated. Large parties that walk in without advance notice may cause interruptions in 
service because the restaurant may have to hold tables empty (and forgo potential revenue) while waiting for other adjacent tables to become available. ${ }^{4}$

\section{Call-ahead Seating}

Under a call-ahead-seating policy, customers telephone the restaurant in advance of their arrival (usually on the same day) to hold a place on the waitlist. Customers are not promised a table immediately upon arrival (i.e., they do not have a formal reservation), but they have the benefit of a much shorter wait than if they walked in without calling. Restaurants can use this policy to spread demand to lessbusy times (particularly if the restaurant dictates or negotiates the customer's arrival time) and can also benefit from increased cover counts because the restaurant does not have to hold empty tables, as would be the case with formal reservations.

\section{Issues to Consider}

The waitlist-management techniques described above may help to increase revenue in the short term, but if customers perceive the techniques to be unfair, they may be reluctant to return, diminishing the restaurant's long-term prospects, as mentioned above. Customers base their perceptions of fairness on the following three factors: reference transactions (the way the customers expect the transaction to be conducted), social justice (making sure the policy and the outcome are fair for everyone involved), and familiarity with the policy.

We first discuss research on the impact of violations of the reference transaction on fairness perceptions, followed by a discussion of social-justice principles and how they affect customers' evaluation of a firm's policies and their treatment based on those policies. Finally, we review the literature on how familiarity with (or knowledge of) a policy affects fairness perceptions.

\section{Reference Transaction}

Research has shown that reference transactions are usually based on past experiences with similar situations. ${ }^{5}$ For example, if a restaurant has always served its waiting customers on the basis of first come, first served, that becomes the customers' reference transaction. Violations of the reference transaction occur when a firm behaves differently than what the customer is expecting, regardless of whether the restaurant actually did something expressly unfair. ${ }^{6}$ When the firm violates a reference transaction, customers are likely to consider that firm to be behaving unfairly. For example, a restaurant that takes reservations only for large parties will seat those parties ahead of waiting customers. However, if the waiting customers' reference transaction is first come, first served, they may think it is unfair that the restaurant seats, say, large parties ahead of them, even though the restaurant is following established policy and, therefore, behaving fairly_at least, by its rules.

\section{Social Justice}

When customers evaluate the fairness of a transaction, they consider both the policy that forms the basis for the transaction and the outcome of the transaction. ${ }^{7}$ Customers may think that a policy is fair (procedural justice), but after experiencing the policy firsthand, they may decide that the outcome is unfair (distributive justice). For example, customers may think it is fair for a restaurant to require a deposit to reserve a table for Mother's Day brunch, but if they are actually charged for 
not showing up for their reservation, they may think they are being treated unfairly. They may also judge the policy to be unfair but be pleased with the outcome. ${ }^{8}$

\section{Familiarity}

The more familiar a customer is with a transaction, the greater the likelihood that he or she will view the transaction as being fair and the more sensitive he or she will become to changes in that transaction. Familiarity comes from experiencing similar transactions over time. Depending on how sensitive customers are to changes in the reference transaction, repeated implementation of a revised policy can result in eventually shifting the reference transaction to match a different experience. For example, customers in 1994 viewed revenue-management pricing practices as significantly less fair for hotels than for airlines. When the same survey was repeated in 2002, after hotel revenue management had become more common, there was no difference between the perceived fairness for revenue management in the two industries. ${ }^{10}$

In addition, if a customer has complete information about a policy, his or her fairness ratings tend to be higher than if information is withheld. ${ }^{11}$ Even if customers are unfamiliar with a restaurant's policy, perceived fairness may increase with the amount of information the customer is provided before he or she experiences the policy firsthand. This could be as simple as an explanation from the hostess or as broad as a TV ad campaign marketing a chain restaurant's call-ahead seating program.

\section{The Study}

We tested customer-fairness perceptions of the four waitlist-management policies (i.e., seating by party size, giving pri- ority to VIPs, large-party reservations, and call-ahead seating) using a scenariobased survey. We developed two different scenarios for each policy, one in which the respondent received the advantage of a shorter wait and one in which the respondent had a longer wait (disadvantage). As described in Exhibit 1, the scenarios for each policy were identical except that in one scenario, the respondent was with a party that was seated right away, and in the other, the respondent was with the party that had to wait. All eight scenarios were designed so that the respondents knew the reason that the restaurant made the choice of whom to seat first.

We stopped people at the Ithaca Farmers Market and asked whether they would be willing to participate in a student research project. People who agreed to participate were given a survey with one of the scenarios and were asked to evaluate the fairness of the outcome, rate the fairness of the policy, and indicate their familiarity with the practice. All questions were ranked on 7-point scales. ${ }^{12}$ As a check against certain sample biases, the questionnaire included questions on age, gender, and frequency of dining out. Analysis showed that none of those demographic factors influenced the responses. ${ }^{13}$ Our survey methodology resulted in a convenience sample of 268 respondents. The majority (58 percent) of respondents was female, and respondent age was fairly evenly distributed. Most customers had eaten out five to ten times during the previous month.

\section{Results}

Customers' perceptions of the fairness of the waitlist-management policies we studied are presented in Exhibits 2, 3, and 4. After the discussion of overall fairness ratings, we discuss the respondents' perceptions of procedural- and distributive- 


\section{Exhibit 1:}

Survey Scenarios

\begin{tabular}{|c|c|c|}
\hline & Advantage & Disadvantage \\
\hline Party size & $\begin{array}{l}\text { Imagine you are dining with a party of four } \\
\text { at a restaurant that does not take reser- } \\
\text { vations. Tonight the restaurant is busy, } \\
\text { so they are using a waitlist. A party of } \\
\text { two arrives just ahead of you, and is } \\
\text { asked to wait. Your party of four is } \\
\text { seated immediately at the only open } \\
\text { table in the restaurant, which is a table } \\
\text { for four. You notice the party of two still } \\
\text { waiting at the bar. }\end{array}$ & $\begin{array}{l}\text { Imagine you are dining with a party of two } \\
\text { at a restaurant that does not take reser- } \\
\text { vations. Tonight the restaurant is busy, } \\
\text { so they are using a waitlist. When your } \\
\text { party of two arrives at the restaurant, } \\
\text { you are asked to wait for a table. You } \\
\text { notice that a party of four that arrived } \\
\text { just after you is seated immediately at } \\
\text { the only open table in the restaurant, } \\
\text { which is a table for four. }\end{array}$ \\
\hline VIP & $\begin{array}{l}\text { Imagine you are dining with a party of four } \\
\text { at a restaurant that does not take reser- } \\
\text { vations. Tonight the restaurant is busy, } \\
\text { so they are using a waitlist. You are din- } \\
\text { ing with the town police chief, who is } \\
\text { very well known in the community. A } \\
\text { party of four arrives just ahead of you } \\
\text { and is asked to wait. Your party is imme- } \\
\text { diately seated at the only open table in } \\
\text { the restaurant, which is a table for four. } \\
\text { You notice that the party of four that } \\
\text { arrived ahead of you is still waiting at } \\
\text { the bar. }\end{array}$ & $\begin{array}{l}\text { Imagine you are dining with a party of four } \\
\text { at a restaurant that does not take reser- } \\
\text { vations. Tonight the restaurant is busy, } \\
\text { so they are using a waitlist. Your party } \\
\text { of four is asked to wait. You notice the } \\
\text { town police chief, who is very well } \\
\text { known in the community, coming in } \\
\text { right after you with a party of four. The } \\
\text { party of four that includes the police } \\
\text { chief is immediately seated at the only } \\
\text { open table in the restaurant, which is } \\
\text { table of four. Your party is still waiting } \\
\text { for a table. }\end{array}$ \\
\hline Large party & $\begin{array}{l}\text { Imagine you are planning dinner with a } \\
\text { party of eight at a local restaurant. When } \\
\text { you call them for information before- } \\
\text { hand, you discover that the restaurant } \\
\text { only takes reservations for parties of six } \\
\text { or greater. You make a reservation. } \\
\text { When you arrive at the restaurant, you } \\
\text { notice that there is a party of four wait- } \\
\text { ing for a table. Your party of eight is } \\
\text { seated immediately. }\end{array}$ & $\begin{array}{l}\text { Imagine you are planning dinner with a } \\
\text { party of four at a local restaurant. When } \\
\text { you call them for information before- } \\
\text { hand, you discover that the restaurant } \\
\text { only takes reservations for parties of six } \\
\text { or greater. When you arrive at the res- } \\
\text { taurant, the hostess tells your party that } \\
\text { there is a wait. A party of eight arrives } \\
\text { after you and is seated immediately. }\end{array}$ \\
\hline
\end{tabular}

justice issues and then the effect of familiarity on fairness ratings.

\section{Social Justice}

Customers rated seating by party size and call-ahead policies as being relatively fair. Taking reservations only for large parties was viewed as neutral to slightly unfair, but giving priority to VIP customers was viewed as unfair (see Exhibits 2 and 4). While there appears to be some difference in the fairness ratings between customers who did not have to wait (advantage) and those who did (disadvantage), the differences were not statistically 


\section{Exhibit 2:}

\section{Procedural Justice}

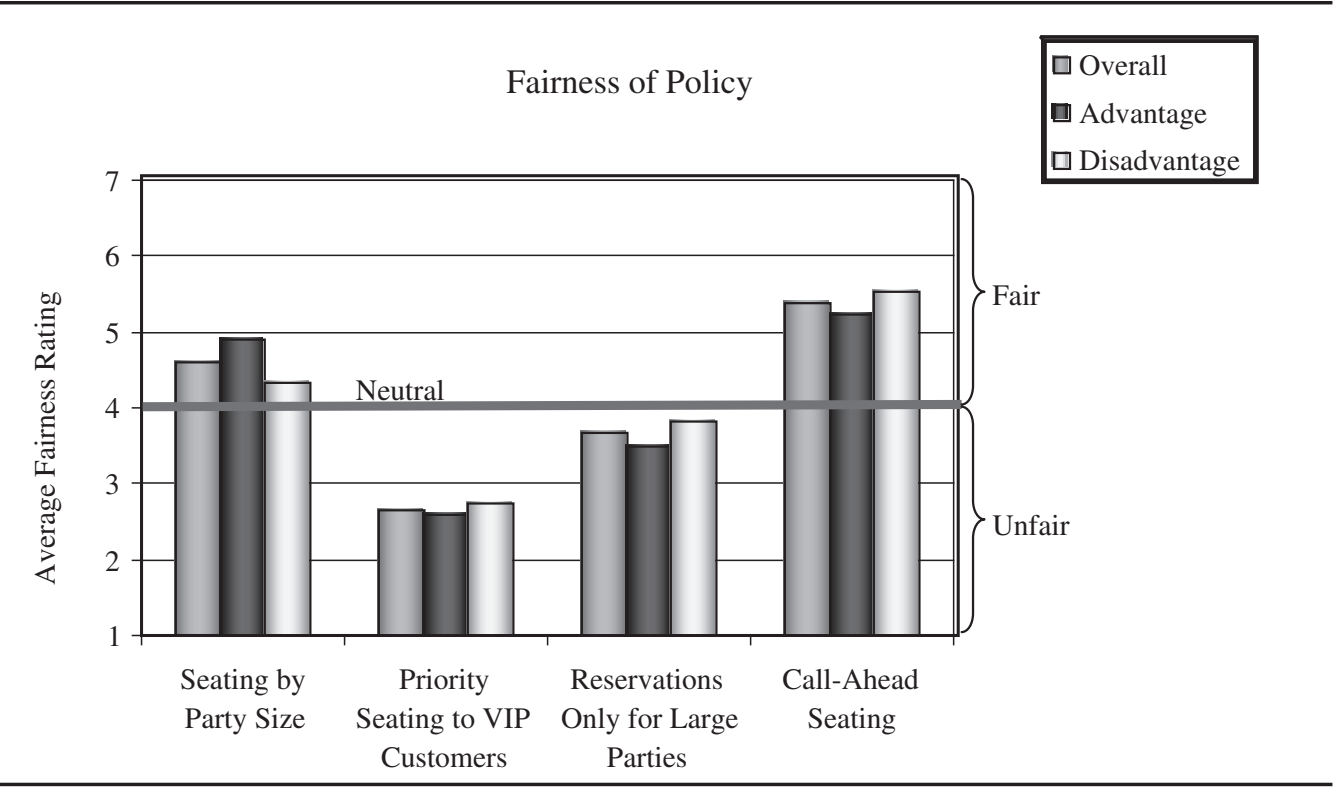

Exhibit 3:

Distributive Justice

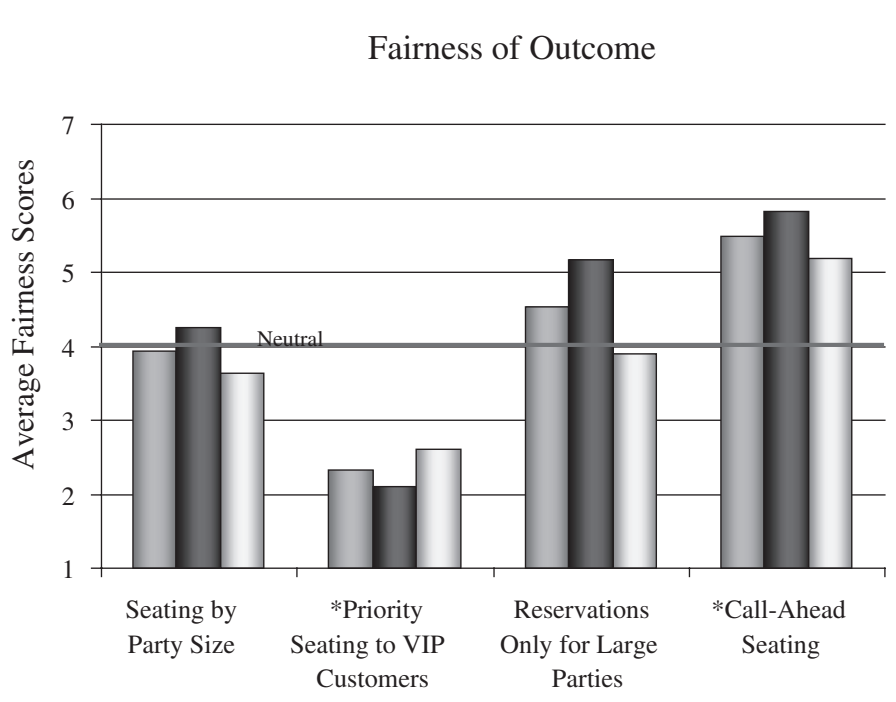




\section{Exhibit 4:}

Means for Fairness Ratings

\begin{tabular}{|c|c|c|c|c|}
\hline \multirow[b]{3}{*}{ Waitlist-management Technique } & \multicolumn{4}{|c|}{ Fairness Ratings } \\
\hline & \multicolumn{2}{|c|}{ Distributive } & \multicolumn{2}{|c|}{ Procedural } \\
\hline & Mean & $\begin{array}{l}\text { Standard } \\
\text { Deviation }\end{array}$ & Mean & $\begin{array}{l}\text { Standard } \\
\text { Deviation }\end{array}$ \\
\hline \multicolumn{5}{|l|}{ Seating by party size ${ }^{* *}$} \\
\hline Overall & 3.94 & 1.84 & 4.61 & 1.65 \\
\hline Advantage & 4.26 & 2.02 & 4.89 & 1.83 \\
\hline Disadvantage & 3.63 & 1.61 & 4.32 & 1.41 \\
\hline \multicolumn{5}{|l|}{ Priority seating to VIP customers } \\
\hline Overall & 2.32 & $1.52 *$ & 2.65 & $1.69 *$ \\
\hline Advantage & 2.11 & 1.44 & 2.58 & 1.75 \\
\hline Disadvantage & 2.60 & 1.59 & 2.73 & 1.64 \\
\hline \multicolumn{5}{|c|}{ Reservations only for large parties*** } \\
\hline Overall & 4.53 & 2.08 & 3.66 & $1.91 *$ \\
\hline Advantage & 5.17 & $1.97 * *$ & 3.48 & 2.03 \\
\hline Disadvantage & 3.90 & 2.02 & 3.83 & 1.80 \\
\hline \multicolumn{5}{|l|}{ Call-ahead seating } \\
\hline Overall & 5.49 & $1.55^{*}$ & 5.39 & 1.54 \\
\hline Advantage & 5.82 & 1.45 & 5.24 & 1.58 \\
\hline Disadvantage & 5.19 & 1.60 & 5.53 & 1.52 \\
\hline
\end{tabular}

significant (Exhibit 2), indicating that customers felt the same about the policies whether they were seated first or not. ${ }^{14}$

Fairness of the outcome. Customers ranked the fairness of the outcome similarly to the fairness of the policy (Exhibits 3 and 4). Call-ahead seating was still considered fair, while VIP seating was still considered unfair. Seating by party size and large-party reservations were rated as neutral. However, for large-party reservations, advantaged customers ranked the outcome as significantly fairer than did those customers who had to wait longer. ${ }^{15}$

Comparison of procedural- and distributive-justice ratings. Next, we com- pared the ratings for procedural justice to those for distributive justice (Exhibit 4). Customers did not see a difference between the fairness of the policy and the fairness of the outcome in call-ahead and VIP seating scenarios. However, there were some differences between policy and outcome ratings for party size and largeparty reservations. ${ }^{16}$

Respondents judged the policy of seating by party size to be slightly fairer than the outcome of that policy, whether the respondent was in the party seated first or the one that had to wait. The reverse was true for large-party reservations, where the outcome was rated as being fairer than the policy itself, particularly among the respondents who did not have to wait (Ex- 
Exhibit 5:

Impact of Familiarity on Fairness

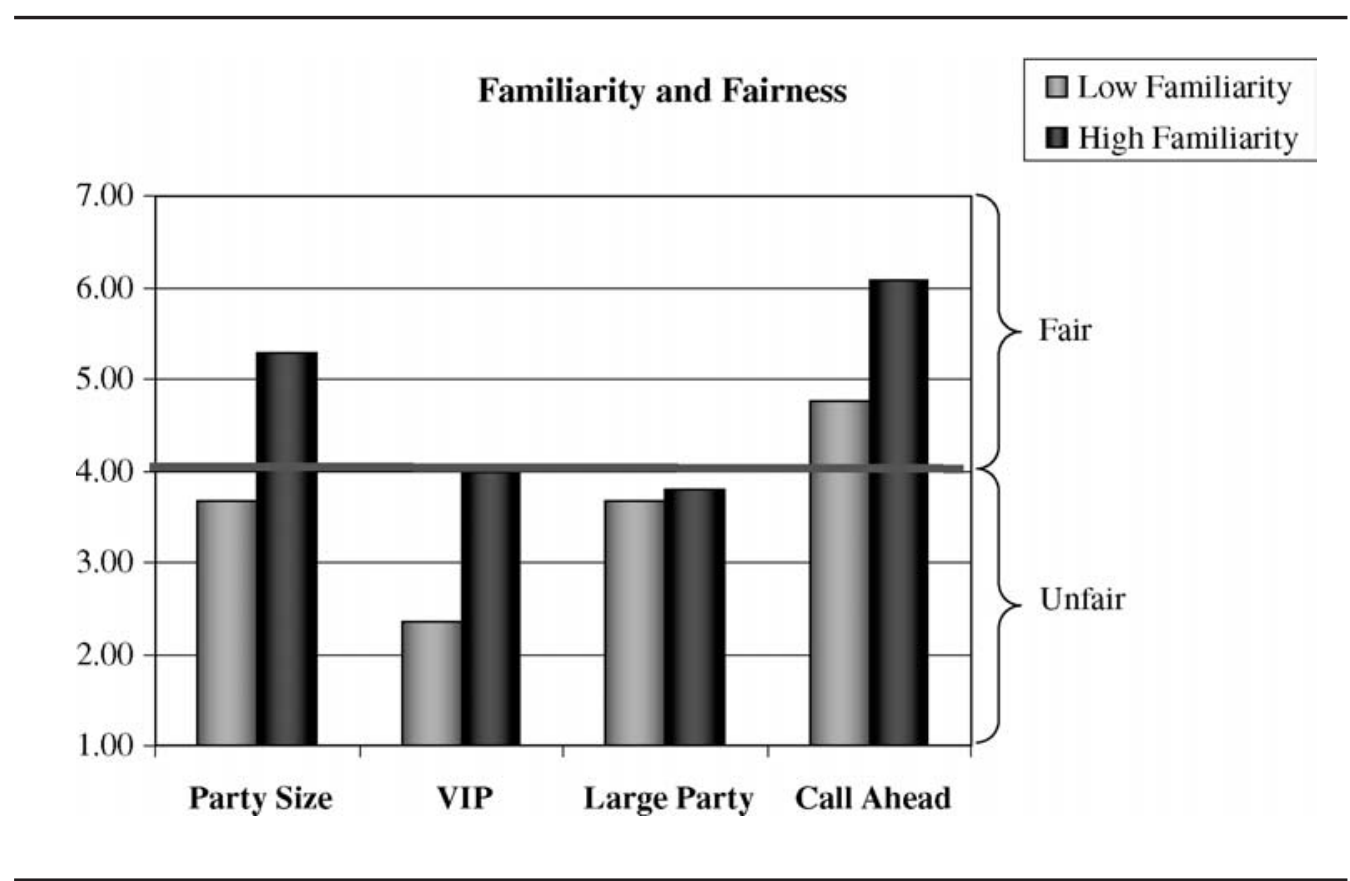

hibit 4). These results indicate that respondents felt that since they had a reservation, it was fair for the restaurant to seat them ahead of waiting parties, but they considered the policy of restricting reservations only to large parties to be unfair.

\section{Familiarity}

We also studied the impact of respondents' familiarity with each waitlist policy on fairness perceptions relating to that policy. For this comparison, we restricted the analysis to those respondents who said they were very familiar with the waitlist policy (scored 6 or 7) and those who indicated they were not familiar with that policy (scored 1 or 2). In all cases except for large-party reservations, customers with high familiarity ranked the waitlist policies as fairer than did those with low familiarity (Exhibit 5).
Accepting large-party reservations was considered slightly unfair regardless of whether respondents were familiar with the practice. Seating by party size was considered slightly unfair by those not familiar with the policy but was considered fair by those familiar with the policy. Callahead seating was considered slightly fair by those indicating low familiarity and very fair by those with high familiarity. While fairness perceptions for VIP seating did increase with familiarity, the policy was rated unfair by those not familiar with it and neutral at best for those with some exposure to the practice (Exhibit 5). ${ }^{17}$

\section{Implications for Managers}

The results of this study show that managers can implement policies that can help increase revenue without damaging customer satisfaction. However, some techniques managers should either avoid or 
exercise caution in using, as we explain below.

\section{Party Size}

Managers should consider seating customers by party size since our respondents rated that practice as being relatively fair. However, given that respondents who said they were unfamiliar with party-size seating indicated that they thought the policy was slightly unfair, it is important that restaurants make an effort to increase customers' familiarity with the practice. One way to set the desired customer expectations would be a statement, such as, "There is a wait for tables right now, but we'll put you on the list for the next available table for two." Before beginning to use this technique, managers should be certain that the number of tables allocated to each party size corresponds to the restaurant's party-size mix, so that the wait will not be too long for the customers who get passed over for a right-sized party. ${ }^{18}$

\section{VIP Customers}

Any VIP seating policy should be handled carefully. The strong negative rating for VIP seating (as compared with all other scenarios) indicates that customers are not comfortable with restaurants' giving priority to customers strictly on the basis of status. Even when respondents had an advantage in the VIP scenario (meaning they were with the VIP and did not have to wait), they still thought the outcome was unfair.

Restaurant managers might have many reasons to give priority seating to VIP customers, but managers should attempt to mask any such special treatment as much as possible to avoid the negative reaction accorded this policy. Techniques such as having customers wait in a location away from the hostess stand, bringing VIPs through a separate entrance, or using pagers to call the next party to be seated may prevent customers from tracking their exact place in line so that they will not notice other customers' being seated ahead of them. For example, Universal Studios brings VIP customers through the exits of its rides so that most customers in the regular line are not aware that the first-come, first-served queue has been violated. ${ }^{19}$

\section{Reservations Only for Large Parties}

Taking reservations only for large parties may be risky for restaurants, if only because it is more difficult to mask than offering VIP seating can be. Large-party reservations were the only waitlistmanagement policy where familiarity with the policy did not influence respondents' judgment regarding fairness. Regardless of familiarity, respondents viewed large-party reservations as being unfair, and this rating did not improve at all with increases in familiarity. We suggest that a possible explanation for this finding is a general expectation among customers that if reservations are taken, then parties of any size should be able to make them. If this assumption is correct, customers would consider it unfair for a restaurant to restrict reservations only to large parties.

That said, restaurateurs are well aware of the benefits of knowing ahead of time when large parties will arrive. To avoid the unfairness perception found in this study, the restaurant could use call-ahead seating for all parties, which could provide some advance warning for large parties while addressing customers' fairness concerns.

\section{Call-ahead Seating}

Restaurants that use call-ahead seating should make sure that this policy is explained carefully and understood by cus- 
tomers. Call-ahead seating was rated the fairest policy in the study, and while it was considered slightly fair by customers who were not familiar with the practice, it was ranked significantly fairer by customers with high familiarity.

Respondents in this study reported a relatively high familiarity with call-ahead seating policies, as compared with the other policies in the study. While this may have been due to the fact that a popular local restaurant has been using call-ahead seating for years, many chain restaurants also use this approach, which has become a common industry practice. ${ }^{20}$ Restaurants should make sure not only that they promote the fact that they use call-ahead seating but also, since the definitions of how it is used vary, that they are clear on the rules in effect.

\section{Implications for Researchers}

The results of this study provide mixed support for previous research on reference transactions, social-justice issues, and familiarity perceptions.

\section{Reference Transaction}

The finding that some of the waitlistmanagement techniques are viewed as fair seems inconsistent with research on reference transactions (assuming that first come, first served is the reference transaction). ${ }^{21}$ This suggests the need for additional research on customers' reactions to the violation of reference transactions, an examination of what exactly is the reference transaction, or an investigation of whether reference transactions are even at play under these circumstances.

\section{Social Justice}

The scenarios were designed so that one party always gained an advantage from the policy (i.e., was seated right away) while the other was disadvantaged. Social-justice research suggests that customers are sensitive to unequal outcomes and, furthermore, that customers at a disadvantage in a scenario tend to consider it to be less fair than do customers who received an advantage. ${ }^{22}$ This result was only partially supported in our study. Only in the case of large-party reservations did the relative advantage of the outcome make a difference in respondents' view of a policy's fairness. This suggests either that respondents felt that the other seating policies contained a relatively equivalent exchange for all parties or that further research is needed on the impact of relative advantage in violations of the reference transaction.

\section{Familiarity}

The finding that the more familiar customers are with a waitlist-management policy, the fairer they think it is (with the exception of large-party reservations), is consistent with previous research. ${ }^{23}$ Even so, respondents were at best neutral toward VIP seating, and those who were unfamiliar with the VIP policy considered it unfair. Therefore, it is important to remember that customers still may not think a policy is fair, regardless of how familiar they are with it.

\section{Limitations and Future Research}

This study has several limitations. First, the study was conducted outside the restaurant environment, at a farmer's market. We did this because we were afraid that had we conducted the test in a restaurant, the survey scenarios might have negatively influenced customers' feelings about that restaurant. This means, however, that respondents may have been more forgiving in their fairness ratings 
than they would have been if they had just experienced some form of queue manipulation. Also, since the survey was conducted primarily in Ithaca, New York, it is possible that the survey is biased toward the attitudes of the local residents, which may not be representative of the attitudes of the entire country.

In addition, the identity of the "VIP" for the VIP-seating scenarios (in this case, the local police chief) may have affected customer responses. Customers might have been more forgiving of the restaurant's giving priority to a Hollywood celebrity, to a politician, or to them personally if they were the VIP customer. Furthermore, ratings may have been different if the restaurant were rewarding loyalty by treating frequent diners as VIP customers.

Future research should address the issue of customers' preferences about callahead seating, particularly because it is unclear in this study whether customers made a distinction between call-ahead seating and formal reservations. Also, given the fairness ratings of the largeparty-reservation scenarios, it would be interesting to determine how much of the customer base would prefer to make reservations when eating out or, for that matter, what percentage of customers would not go to any restaurant where they are unable to make a reservation.

The VIP results present an interesting opportunity for future research as well. Customer tolerance for VIP treatment should be studied for a variety of different types of people (i.e., celebrities, loyal customers, pregnant or elderly people, and parties with children) since fairness ratings may vary depending on the type of VIP customer.

Even though respondents deemed two of the policies we tested to be fair, it was unclear from this study whether those re- spondents actually consider first come, first served to be their reference transaction when there is a waitlist or whether they simply did not perceive violations of this reference transaction to be unfair. If the violation is not considered to be unfair, that would go against previous research findings indicating that customers are sensitive to violations of the reference transaction. More research can be conducted in this area to determine, first, what customers consider to be the reference transaction in restaurant waiting situations and, second, if the reference transaction is indeed first come, first served, why diners would permit certain types of violations but not others. In addition, since relative advantage was shown not to make a difference in our study, more research should be conducted on the relationship between relative advantage and violations of the reference transaction.

Social justice studies have focused primarily on employee compensation or transactions that can be tied back to compensation, such as performance ratings and disciplinary actions, ${ }^{24}$ and the fairness literature has focused on fairness in pricing strategies, such as demand based pricing. ${ }^{25}$ In this study, the scenarios included no direct financial implications but simply showed a departure from principles established in previous social justice and fairness studies. Our results seem to indicate, therefore, that customers react differently to violations of the reference transaction in situations where pricing is not an issue. Since this is one of the first studies to address the reference transaction separately from the reference price, more research in this area is needed to further understand the difference between reference transaction violations that have financial implications and those that do not. 


\section{Summary and Conclusions}

While waitlist-management techniques can help managers to make the important decision of seating the right customer at the right time, a restaurant could be sacrificing long-term profitability for shortterm revenue gains if the customer base reacts unfavorably to any techniques that seem unfair. Restaurant managers should consider fairness ratings when determining the appropriate waitlist-management policy for their operation so that they do not implement a policy that will diminish customer satisfaction.

Based on our study, customers feel that taking reservations only for large parties is slightly unfair, so restaurants should carefully consider whether they want to implement this policy. Given the advantage of knowing in advance that a large party is coming, restaurateurs might wish to mask a large-party reservation policy by using call-ahead seating for all customers. VIP seating was considered relatively unfair, so managers need to be cautious about this policy as well. Restaurateurs who seat VIPs preferentially should try to keep this treatment out of the view of the rest of the customer base so as not to affect overall customer satisfaction.

Seating by party size and call-ahead seating were considered relatively fair by the respondents. However, those who were highly familiar with these waitlistmanagement policies rated them as significantly fairer than those with low familiarity. Therefore, when using call-ahead seating or party-size seating, managers should be sure to let the customers know exactly how these procedures operate.

This study is an important first step in understanding customers' fairness perceptions of certain waitlist-management techniques, but there are many areas left to explore. Research on customers' reactions to VIP treatment, for example, would help managers understand how to make their VIPs feel special without alienating other customers. Further research can also be conducted into customers' preferences about making reservations when they dine out, as opposed to eating at restaurants that do not take reservations. Even before this additional research is conducted, this study gives managers some guidance regarding how to make the most of their waiting customers without diminishing long-term customer satisfaction.

\section{Endnotes}

1. The National Restaurant Association indicates that approximately 15 percent of all restaurants are categorized as fine dining. Since finedining restaurants tend to take reservations and book out during high-demand times, it can be inferred that around 85 percent of restaurants rely on walk-in business.

2. R. F. Thaler, "Mental Accounting and Consumer Choice," Marketing Science 4, no. 3 (1985): 199-214; D. Kahneman, J. L. Knetsch, and R. Thaler, "Fairness as a Constraint on Profit Seeking: Entitlements in the Market," The American Economic Review 76, no. 4 (September 1986): 728-41; J. E. Urbany, T. J. Madden, and P. R. Dickson, "All's Not Fair in Pricing: An Initial Look at the Dual Entitlement Principle," Marketing Letters 1, no. 1 (1989): 17-25; P. J. Kaufmann, G. Ortmeyer, and N. C. Smith, "Fairness in Consumer Pricing," Journal of Consumer Policy 14 (1991): 117-40; S. E. Kimes, "Perceived Fairness of Yield Management," Cornell Hotel and Restaurant Administration Quarterly 29, no. 1 (February 1994): 22-29; M. C. Campbell, "Why Did You Do That? The Important Role of Inferred Motive in Perceptions of Price Fairness," Journal of Product and Brand Management 8, no. 2 (1999): 145-52; M. C. Campbell, "Perceptions of Price Unfairness: Antecedents and Consequences," Journal of Marketing Research 36, no. 2 (1999): 187-99; S. E. Kimes and J. Wirtz, "Perceived Fairness of Demand Based Pricing for Restaurants," Cornell Hotel and Restaurant Administration Quarterly 43, no. 1 (2002): 31-38; S. E. Kimes and J. Wirtz, "Perceived Fairness of Revenue Management in the U.S. Golf Industry," Journal of Revenue and Pricing Management 1, no. 4 (2002): 33244; and S. E. Kimes and J. Wirtz, "Has Reve- 
nue Management Become Acceptable?” Journal of Service Research 10, no. 10 (2003): 1-11.

3. S. E. Kimes and G. M. Thompson, "Restaurant Revenue Management at Chevys: Determining the Best Table Mix," Decision Sciences 35, no. 3 (2003): 371-92.

4. S. E. Kimes, S. Choi, E. N. Ngonzi, and P. Y. Lee, "Restaurant Revenue Management," Cornell Hotel and Restaurant Administration Quarterly 39, no. 3 (June 1998): 40-45.

5. See Kahneman, Knetsch, and Thaler, "Fairness as a Constraint."

6. Ibid.

7. S. Tax, S. Brown, and M. Chandrashekaran, "Customer Evaluation of Service-complaint Experiences: Implications for Relationship Marketing," Journal of Marketing 62, no. 2 (1998): 60-76; A. Smith, R. Bolton, and J. Wagner, "A Model of Customer Satisfaction with Service Encounters Involving Failure and Recovery," Journal of Marketing Research 34 (1999): 356-72; and B. A. Sparks and J. McColl-Kennedy, "Justice Strategy and Options for Increased Customer Satisfaction in a Services-recovery Setting," Journal of Business Research 54, no. 3 (2001): 209-18.

8. J. Greenberg, "A Taxonomy of Organizational-justice Theories," Academy of Management Review 12 (1987): 9-22; and J. Greenberg, "Organizational Justice: Yesterday, Today, and Tomorrow," Journal of Management 16 (1990): 339-432.

9. N. M. Klein and J. E. Oglethorpe, "Cognitive Reference Points in Consumer Decision Making," Advances in Consumer Research 14 (1987): 183-87; K. Van den Bos, R. Vermunt, and H. A. M. Wilke, "The Consistency Rule and the Voice Effect: The Influence of Expectation on Procedural Fairness Judgments and Performance," European Journal of Social Psychology 26 (1996): 411-42; K. Van den Bos, R. Vermunt, and H. A. M. Wilke, "Procedural and Distributive Justice: What's Fair Depends More on What Comes First than on What Comes Next," Journal of Personality \& Social Psychology 72, no. 1 (1997): 95-104; and J. Wirtz and S. E. Kimes, "The Psychology of Revenue Management: Impact of Familiarity, Framing, and Fencing Condition on the Perceived Fairness of Rate Fences" (Working paper submitted to Journal of Marketing, 2004).

10. Kimes, "Perceived Fairness of Yield Management"; and S. E. Kimes and B. M. Noone, "Perceived Fairness of Yield Management: An
Update," Cornell Hotel and Restaurant Administration Quarterly 43, no. 1 (February 2002): 28-29.

11. Kaufmann, Ortmeyer, and Smith, "Fairness in Consumer Pricing"; Campbell, "Why Did You Do That?"; Campbell, "Perceptions of Price Unfairness"; and Van de Bos, Vermunt, and Wilke, "Procedural and Distributive Justice."

12. The fairness question ranges from 1 (very unfair) to 7 (very fair), and familiarity ranges from 1 (very unfamiliar) to 7 (very familiar).

13. ANOVA was used to determine the statistical significance of all of the results. Where applicable, Tukey's method was used to determine which pairs of means were statistically significantly different from each other.

14. At $p<0.05$.

15. All tests are significant at $p<0.05$.

16. Paired $t$ tests were used to compare the means for distributive- and procedural-justice fairness scores. The differences, calculated as (distributive-justice score - procedural-justice score), are significant at $p<0.05$.

17. All significant at $p<0.05$.

18. Kimes and Thompson, "Restaurant Revenue Management at Chevys."

19. R. Setoodeh, "Step Right Up! Amusementpark Visitors Pay Premium to Avoid Long Lines; Some Have-Nots Are Miffed," Wall Street Journal, July 12, 2004, B1.

20. B. Krummert, "Rush Hour," Restaurant Hospitality, July 2003, 43-48.

21. Kahneman, Knetsch, and Thaler, "Fairness as a Constraint."

22. J. S. Adams, "Inequity in Social Exchange," Advances in Experimental Social Psychology 2 (1965): 267-99; R. P. Bagozzi "Marketing as Exchange," Journal of Marketing 39 (1975): 32-39; R. B. Cialdini, Influence (New York: HarperCollins, 1993); and J. Colquitt, "On the Dimensionality of Organizational Justice: A Construct Validation of a Measure," Journal of Applied Psychology 86, no. 3 (2001): 386-400.

23. Van den Bos, Vermunt, and Wilke, "Procedural and Distributive Justice"; and Wirtz and Kimes, "The Psychology of Revenue Management."

24. See J. Greenberg, "A Taxonomy of Organizational-justice Theories," Academy of Management Review 12 (1987): 9-22; Van de Bos, Vermunt, and Wilke, "The Consistency Rule"; and Van den Bos, Vermunt, and Wilke, "Procedural and Distributive Justice."

25. See Kimes and Wirtz, "Has Revenue Management Become Acceptable?" 


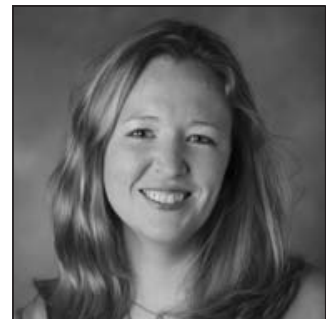

Kelly A. McGuire is a Ph.D. candidate at the Cornell University School of Hotel Administration (kam63@ cornell. edu), where Sheryl E. Kimes, Ph.D., is a professor and interim dean (sek6@cornell.edu). The authors thank Brad Weiss and Sharon Lee for their assistance with data collection and thank the Ithaca Farmers Market for allowing us to conduct the survey at its location.

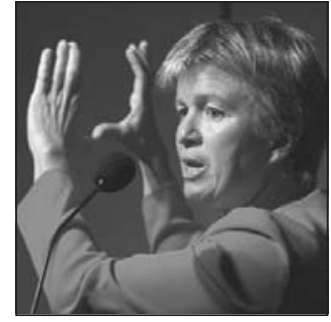

